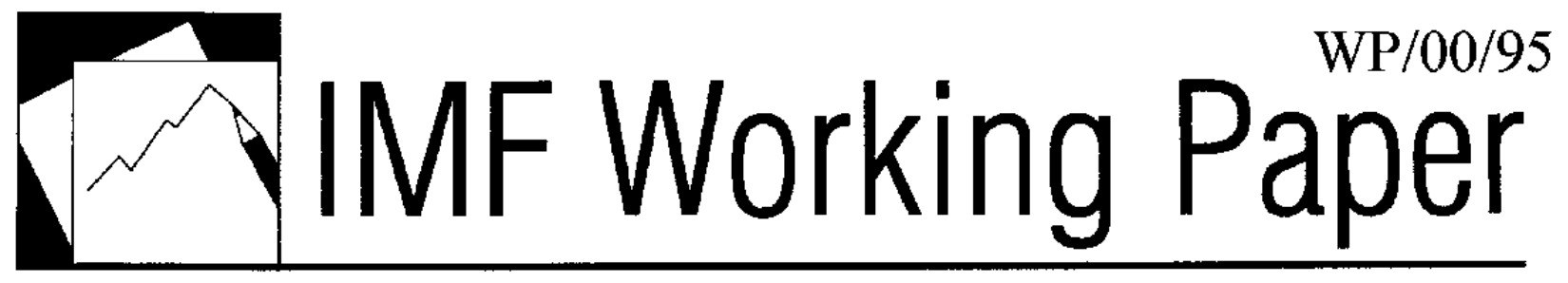

\title{
The Yen-Dollar Rate: Have Interventions Mattered?
}

Ramana Ramaswamy and Hossein Samiei 


\title{
IMF Working Paper
}

Asia and Pacific Department and European I Department

The Yen-Dollar Rate: Have Interventions Mattered?

Prepared by Ramana Ramaswamy and Hossein Samiei ${ }^{1}$

Authorized for distribution by Jonathan D. Ostry and Juha Kähkönen

June 2000

\begin{abstract}
The views expressed in this Working Paper are those of the author(s) and do not necessarily represent those of the IMF or IMF policy. Working Papers describe research in progress by the author(s) and are published to elicit comments and to further debate.
\end{abstract}

Using daily data for 1995-99, this paper estimates a simple forward looking model of the exchange rate to show that foreign exchange interventions have, on the whole, had small but persistent effects on the yen-dollar rate. Contrary to conventional wisdom, sterilized interventions have mattered. Consistent with conventional wisdom, coordinated interventions have a higher probability of success and move the yen-dollar rate by a larger margin than unilateral interventions. A probit model indicates that both an excessive appreciation and depreciation of the yen provoke interventions, and that interventions occur in clusters-if there is one today, there will likely be another tomorrow.

JEL Classification Numbers: E4, F3, F31

Keywords: Interventions, exchange rates, expectations

Authors'E-MailAddress: rramaswamy@imf.org; ssamiei@imf.org

${ }^{1}$ The authors are grateful for comments from Stanley Fischer, Toshitaka Sekine, Masahiko Takeda, and members of the IMF's "Japan Team". This paper will be presented at NBER's "Japan Project" conference in Tokyo in September 2000. 
Contents

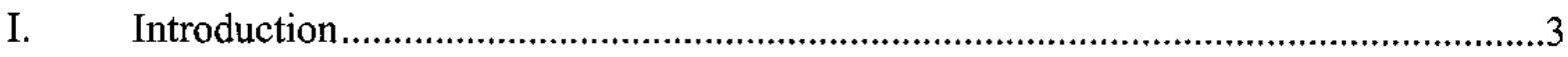

II. Foreign Exchange Interventions in Practice ..........................................................6

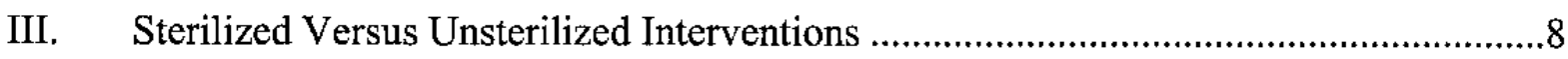

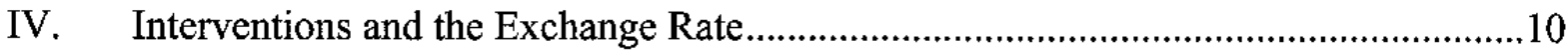

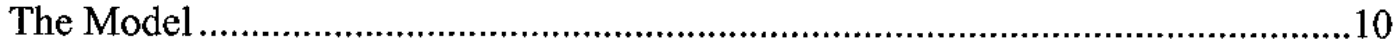

Estimation of the Long-Run Relationship ............................................................11

Error-Correction and Intervention Dummies......................................................12

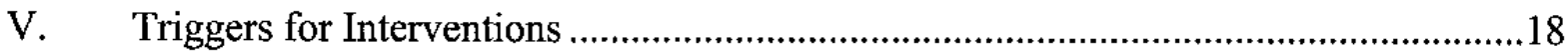

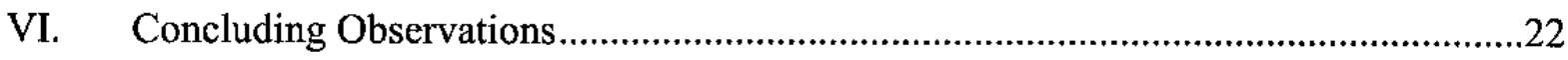

Tables

1. Estimated Error Correction Model of Interventions Based on Cointegrating VAR ....14

2. Parsimonious Estimated Error Correction Model of Interventions Based on

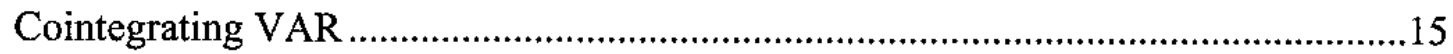

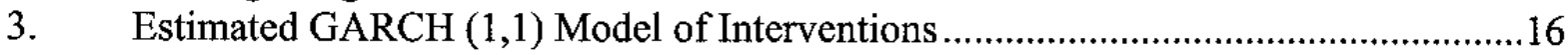

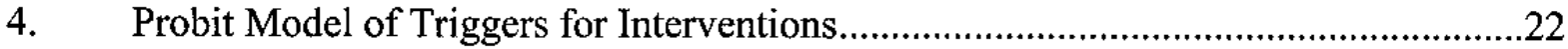

\section{Figures}

1. Japan: Foreign Exchange Interventions in the Yen-Dollar Market ................................5

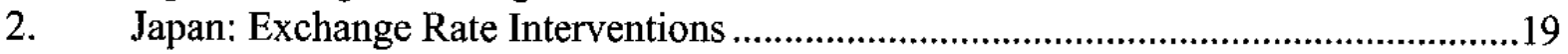

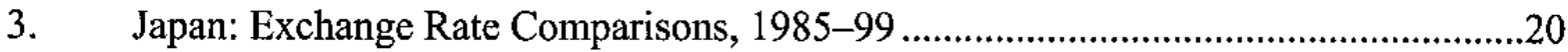

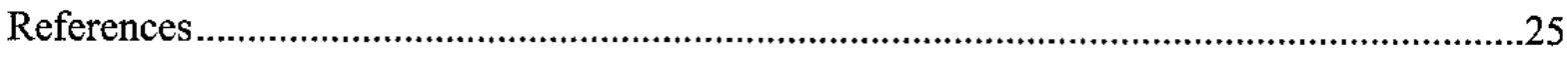




\section{INTRODUCTION}

The yen-dollar rate has been more than just the exchange value of one currency against another. Fluctuations in the yen-dollar rate in the 1980 s, for instance, became enmeshed in an outbreak of trade frictions between Japan and the United States. Swings in the yen-dollar rate have also had systemic effects on the global economy. The sustained depreciation of the yen against the dollar, beginning in mid-1995, eroded the external competitiveness of a number of Asian countries that had pegged their currencies closely to the dollar, and became one of the triggers for the Asian crisis in 1997. More recently, the abrupt appreciation of the yen has threatened to scupper Japan's fragile recovery from its worst post-war crisis, as it did during 1994-95. It is therefore not much of a surprise to find that policy makers in Japan have intervened repeatedly in foreign exchange markets to influence the yen-dollar rate, and that markets have avidly monitored every one of these moves. The critical question, however, is whether these interventions have made a difference to the yen-dollar rate.

Perceptions about the effectiveness of foreign exchange interventions have changed over time. The coordinated interventions that followed the Plaza Accord in September 1985 were followed by a sustained decline in the exchange value of the dollar against the yen; econometric studies indicate that these interventions had a statistically significant impact on exchange rates. ${ }^{2}$ The weakening dollar was, however, not accompanied initially by a reduction in current account imbalances between Japan and the United States, and accentuated trade frictions. This outcome also had the effect initially of generating skepticism about the effectiveness of interventions, even though the success of interventions ought to be measured strictly by their impact on the exchange rate, and not by how the subsequent adjustment process works. However, as noted by Krugman (1991) in a review of developments during this period, the external imbalances between Japan and the United States did subsequently narrow significantly between 1988-90, with the lag being due to "J-Curve" effects."

Despite the post-Plaza Accord experience, doubts about the effectiveness of foreign exchange interventions have lingered, and have come to the fore again recently as the exchange value of the yen has oscillated during the past five years from a highly appreciated

\footnotetext{
${ }^{2}$ Dominguez and Frankel (1993), for instance, use an augmented portfolio balance model, incorporating exchange rate expectations, to show that interventions had a statistically significant impact on exchange rates in the post-Plaza Accord period; interventions are also shown to have mattered during 1982-84, when skepticism about the effectiveness of interventions was pervasive. See, also in this context, Dominguez (1998).

${ }^{3}$ Research at the IMF during this period, for instance, indicated that Japan's external balances throughout 1985-90 responded to exchange rate changes in broadly the same way that they do in other countries, and in a pattern that was broadly consistent with estimated econometric relationships. See, in this context, Corker (1989) and Meredith (1993).
} 
level to a highly depreciated one, and then back again to excessive strength. Despite a series of interventions conducted by the Bank of Japan to weaken the yen during early 1995, it continued to appreciate, reaching a high of about $¥ 80 / \$$ in April 1995 (Figure 1). As dollarbuying operations continued throughout that year, including episodes of coordinated interventions and an easing of monetary policy in Japan, the yen depreciated significantly, crossing the $¥ 125 / \$$ mark in early 1997 . The Japanese authorities soon after had to change strategy, and began instead to intervene to prevent the exchange value of the yen from depreciating further. However, with confidence in the yen dented by the advent of the Asian crisis in July 1997 and the financial panic generated by the bank failures in Japan in late 1997 , the yen continued to depreciate, reaching $¥ 145 / \$$ by August 1998 . The turbulence in global financial markets intensified at that point, resulting in an abrupt unwinding of the socalled "yen-carry-trades", and the yen began to appreciate dramatically, reaching $¥ 110 / \$$ by January 1999. Surrealistically, the Japanese authorities were forced within the span of a few months to shift from a strategy of intervening to strengthen the yen to one of intervening once more to weaken the yen, and periodic dollar buying operations have continued in 2000 .

The foreign exchange interventions carried out in the latter half of the 1990s raise a number of questions. How effective were the foreign exchange interventions? Did they have persistent effects on the yen-dollar rate? Were interventions more effective when coordinated than when conducted unilaterally? Did interventions to strengthen the yen have a greater chance of success than interventions to weaken the yen? Why did the Japanese authorities intervene much more frequently in the yen-dollar market than the U.S. authorities did, and what specifically triggers foreign exchange interventions? The paper attempts to answer these questions, estimating an interest-rate arbitrage rational expectations model of the exchange rate with daily data, and a probit model of the probability of interventions. In contrast to recent studies which have focused on the impact of interventions on exchange rate volatility (Dominguez (1998) and Chang and Taylor (1998)), or have revisited the effectiveness of the Plaza Accord interventions (Humpage (1999)), the focus of this paper is on directly testing the impact of the interventions conducted in recent years on the level of the exchange rate.

The main finding of the paper is that the foreign exchange interventions conducted during 1995-99 have on the whole mattered, and did succeed on a number of occasions in changing the path of the yen-dollar rate in the desired direction, even though the interventions in the yen-dollar market were routinely sterilized. Thus, contrary to the conventional wisdom that interventions can be effective only when left unsterilized, an important finding of the paper is that sterilized interventions appear to work-having a probability of success of about 50 percent. The paper argues that sterilized interventions have been effective primarily because they influence market participants' expectations of future economic fundamentals and the stance of monetary policy, and also erode bandwagon effects. Consistent with conventional wisdom, the paper finds that coordinated interventions in the yen-dollar market have been more effective than unilateral interventions, having a probability of success of about 75 percent; when successful, coordinated interventions move the exchange rate in the desired direction by about 2-3 percent-about thrice as much as unilateral interventions do. While interventions have, on average, had relatively small effects on the yen-dollar rate, these effects tend to be persistent. However, it needs to be noted in this 
Figure 1. Japan: Foreign Exchange Interventions in the Yen-Dollar Market 1/

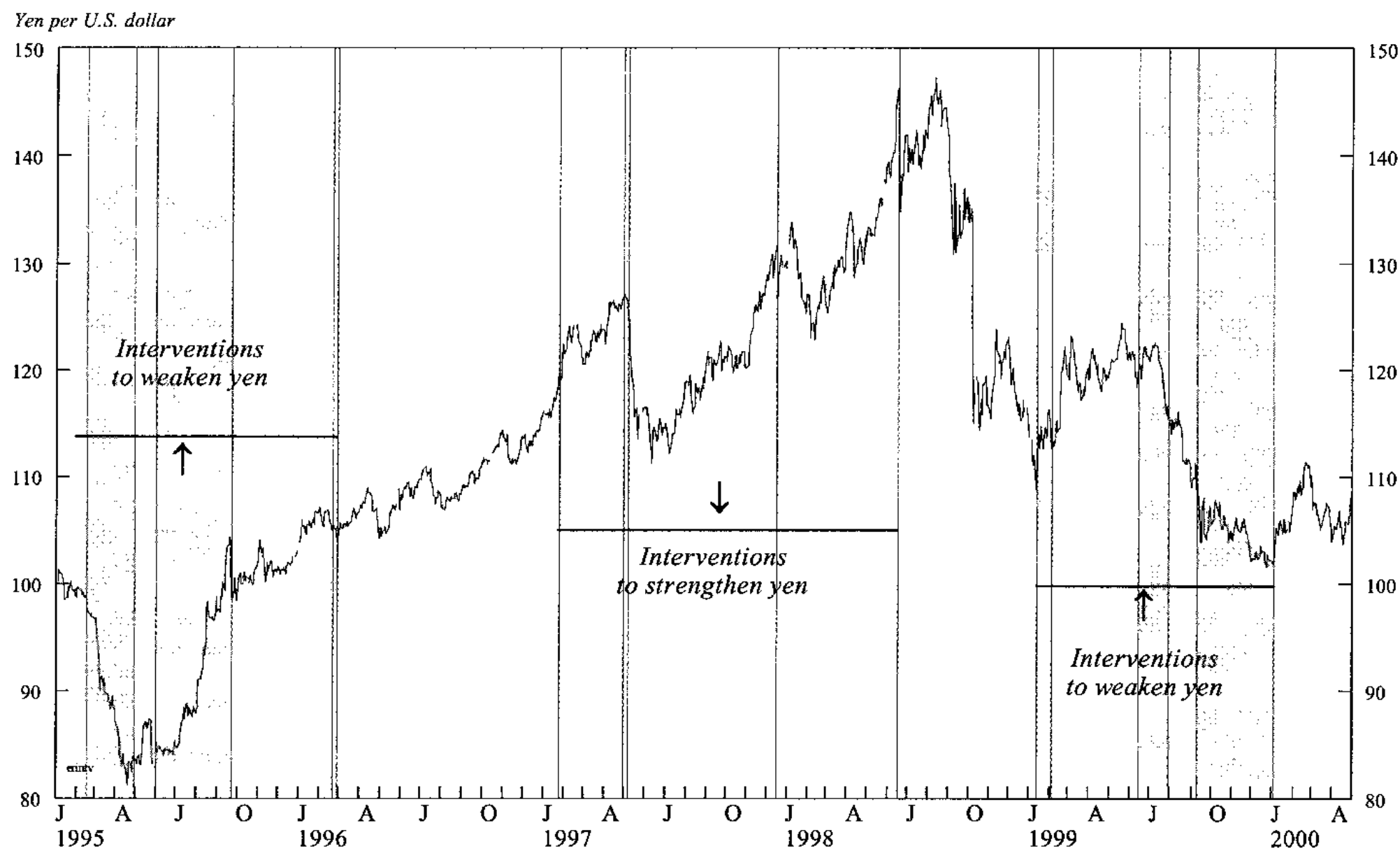


context that the model used for the estimations succeeds in explaining only a relatively small part of the day to day fluctuations in the yen-dollar rate, which like all asset prices, has a significant unexplained component to its movements.

The paper also finds that unilateral interventions by the Bank of Japan to weaken the yen have had a somewhat lower success rate than unilateral actions to strengthen the yen. It is interesting to note in this regard that the Bank of Japan (BoJ) intervenes much more frequently in the yen-dollar market than the Fed does, with much of the interventions aiming to stem yen appreciation. The paper argues that the higher frequency of the BoJ's interventions is related to the fact that Japan's nominal effective exchange rate, unlike that of the United States, moves in close synchronization with the yen-dollar rate; consequently, any strengthening of the yen against the dollar implies a stronger negative shock for the Japanese economy than an appreciation of the dollar against the yen does for the U.S. economy. The probit model used to estimate the triggers for interventions indicates that the Japanese authorities have in practice intervened to stem both an "excessive appreciation" and an "excessive depreciation" of the yen, just as they claim to do in their official pronouncements on exchange rate policy. And, finally, the estimations indicate that interventions in the yendollar market tend to occur in clusters, so that if there has been an intervention today, there is then a good chance that there will be another one tomorrow.

\section{Foreign Exchange Interventions in Practice}

A brief overview of how foreign exchange interventions are conducted in the yendollar market provides a useful starting point for analysis. In the case of Japan, the authorization of the foreign exchange operations, as well as the financing of interventions, is the responsibility of the Ministry of Finance. ${ }^{4}$ The Bank of Japan (BoJ) implements the actual intervention operations in the foreign exchange market. In the United States, both the Federal Reserve (Fed) and the Treasury have independent legal authority to initiate foreign exchange interventions. Nevertheless, the primary responsibility in practice for initiating interventions has rested with the Treasury. The Fed implements the actual interventions through the operations of the Foreign Exchange Desk of the Federal Reserve Bank of New York. The financing of interventions is shared between the Treasury and the Fed. ${ }^{5}$

How can we identify specific interventions in the yen-dollar market? The data on the Fed's intervention operations can be obtained after a lag of about a year, but there are no official data on specific interventions conducted by the BoJ. Indicative information on interventions in the yen-dollar market can, however, be gleaned from the financial press, which provides prominent coverage of these operations soon after they take place. News

\footnotetext{
${ }^{4}$ The recent technical changes in the financing of foreign exchange interventions - the sale of Finance Bills issued by the Ministry of Finance to the public rather than to the BoJ directly-has made no effective difference to how interventions are ultimately financed.

${ }^{5}$ See Cross (1998) for a more detailed description of how foreign exchange interventions are carried out in the United States.
} 
reports of foreign exchange interventions tend to be highly reliable, particularly in the postPlaza Accord period. Both the Fed and the BoJ have for some years now conducted their intervention operations openly and directly in the dealer market, typically with the foreign exchange desks of large commercial banks. While central banks have the option of keeping their operations in the dealer market secret, they have typically chosen not to do so, as the primary objective of the interventions has been to show a presence in the foreign exchange market and indicate a view about exchange rate trends. The interventions are usually reported soon after they occur on Reuters and other news agencies, and then receive prominent coverage in the financial press the next day. While some traders do learn of interventions before they appear on Reuters reports, this lag is usually less than 30 minutes in the yendollar market, so that for all practical purposes interventions become public knowledge soon after they are conducted. Sometimes official statements confirm interventions, but the Japanese authorities have typically not followed this practice. ${ }^{6}$

For this study, information on the occurrence of foreign exchange interventions in the yen-dollar market (by both the BoJ and the Fed) during 1995-99 have been collected from the electronic archives of the Financial Times and the Wall Street Journal. The news reports on interventions in these two newspapers have been cross checked with each other, and also with other news sources. Sometimes there are reports in the financial press about either rumors or threats of interventions in the yen-dollar market. Reports of both rumors and threats of interventions have not been included in compiling the data set on interventions, and only reports that specifically mention that central banks have intervened to either weaken or strengthen the yen have been included. The data on foreign exchange interventions, thus, includes four categories of interventions conducted during 1995-99: (a) unilateral interventions by the $\mathrm{BoJ}$ to weaken the yen; (b) coordinated interventions by the $\mathrm{BoJ}$ and the Fed to weaken the yen; (c) unilateral interventions by the BoJ to strengthen the yen; and (d) coordinated interventions by the BoJ and the Fed to strengthen the yen. No instances of unilateral interventions by the Fed in the yen-dollar market were identified in news reports during this period.

According to reports in the financial press, interventions in the yen-dollar market in the latter half of the 1990 s were predominantly aimed at either preventing or reversing yen appreciation. Of these, unilateral interventions by the BoJ to stop the yen from strengthening far outnumbered coordinated interventions. While we identified about 32 unilateral interventions by the BoJ to prevent yen appreciation, there were only 6 such instances of coordinated interventions by the BoJ and the Fed. There were 9 instances of unilateral interventions by the $\mathrm{BoJ}$, and 2 instances of coordinated interventions by the $\mathrm{BoJ}$ and the Fed to either prevent or reverse yen depreciation. It is, of course, likely that news reports failed to identify some of the interventions that did take place during this period, and also, some of the interventions that were reported to have taken place in the press may well have not have occurred in reality. But such errors of identification are likely to be small, given that central

\footnotetext{
${ }^{6}$ See Cross (1998), Chang and Taylor (1998), and Dominguez (1999) for a more detailed description of central bank intervention operations.
} 
banks, as discussed earlier, have used interventions for explicitly signaling their presence in foreign exchange markets.

\section{STERILIZED VERSUS UNSTERILIZED INTERVENTIONS}

The interventions in the yen-dollar market during this period have typically been sterilized - i.e., not allowed to have an impact on the monetary base and interest rates. While there is no explicit information on whether particular interventions were sterilized or not, central banks in industrial countries have in practice routinely offset the impact of foreign exchange interventions on the stance of monetary policy, as monetary policy has typically been used for achieving low rates of inflation rather than for a particular exchange rate objective. In the case of Japan, for instance, the impact of both yen selling and buying operations ordered by the Ministry of Finance on domestic liquidity is offset by the open market operations of the BoJ in order to maintain its desired level of daily excess reserves. In fact, with zero interest rates, sterilizing foreign exchange interventions has become particularly important to the BoJ, as markets have tended to focus on the level of excess reserves as an implicit indicator of the stance of monetary policy. Likewise, directives to the Foreign Exchange Desk of the Fed to sell dollars are simultaneously combined with directives to the Open Market Desk to mop up the resulting excess liquidity. This does not, however, imply that conditions in the foreign exchange market have had no influence on the monetary policy of industrial countries. Rather, the decision to change the stance of monetary policy, which could be influenced in part by exchange rate developments, has been separated in practice from the decision to intervene in the foreign exchange market. So, a test of the effectiveness of interventions in the yen-dollar market, is for all practical purposes, also a test of the effectiveness of sterilized interventions in this market.

Why should sterilized interventions, contrary to conventional wisdom, be expected to have an impact on the yen-dollar rate? That sterilized interventions can work should not come as a surprise when viewed from a historical perspective. As noted before, academic studies indicate that sterilized interventions were successful in the post-Plaza Accord period. Nevertheless, the persistent skepticism about the effectiveness of sterilized interventions in popular discourse appears to be based on a casual empiricism focusing on selective episodes of interventions, combined with an interpretation of the interest parity condition that underplays the importance of expectations in exchange rate determination.

The interest parity condition is often invoked as the theoretical rationale for the assessment that interventions work only when left unsterilized. Uncovered interest rate parity in its strict form states that, in equilibrium, the currency of the country with a higher interest rate is expected by market participants to depreciate against the currency of the country with the lower interest rate over the relevant time horizon, so that investors are indifferent between holding the two currencies (see below). Under a simple view, sterilized intervention does not affect the interest rate differential, and therefore does not affect the exchange rate. By contrast, unsterilized interventions are expected to impact on the exchange rate because they change interest rate differentials. 
However, because future expectations of the exchange rate enter the interest rate parity condition, the exchange rate is influenced not only by actual changes in monetary policy, but also by expectations of future changes in monetary policy. Consequently, even in the context of the interest rate parity condition, actions that provide signals about the future course of monetary policy should also have an impact on the exchange rate. Sterilized interventions can thus make a difference by providing signals to private agents about the future course of monetary policy. ${ }^{7}$ Indeed, one of the main aims of central banks in carrying out sterilized interventions is to change the path of exchange rates by altering market participants expectations of the future course of monetary policy and economic fundamentals. It needs to be noted, however, that the signaling channel is less likely to be effective in situations where markets perceive the central bank not to be in full concurrence with the decision of the Ministry of Finance to intervene; sterilized interventions, in such situations, are likely to be less effective.

While sterilized interventions can also be expected to have an impact on exchange rates by changing the currency composition of assets held by the private sector-the portfolio balance effect-central bank interventions are too small a fraction of the daily turnover in the foreign exchange markets (typically about 1 percent) for them to make significant changes in the currency composition of assets held by the private sector. This is one of the reasonsbesides the limited availability of daily data on the magnitude of the interventions-why the econometric strategy adopted in this paper focuses on the number and types of interventions in the yen-dollar market rather than on the actual quantities of foreign exchange spent on interventions.

Sterilized interventions can also be effective in circumstances where currencies stay persistently misaligned because bandwagon effects and collective action problems dominate the influence of fundamentals. Market players' decisions in such situations are conditioned by what other participants are likely to do rather than on what the underlying economic conditions warrant. For example, such a situation could emerge when no private agent is willing to be the first to buy or sell a currency that he judges to be misaligned, because of imperfect information about the beliefs of other market participants, or simply due to not wanting to make the first move in a game theoretic "common knowledge" setting. Such misalignments can persist for a considerable length of time as it is individually rational in such circumstances for each market participant not to bet against the market. In these contexts, central banks can overcome the collective action problem by using sterilized intervention to signal their assessment of currency misalignment to the entire market.

\footnotetext{
${ }^{7}$ A comprehensive discussion of the signaling role of sterilized interventions can be found in Mussa (1981). For a discussion of the signaling role of interventions in Japan, see Watanabe (1994).
} 


\section{INTERVENTIONS AND THE EXCHANGE RATE}

This section provides a model of the exchange rate for empirically examining the impact of interventions on the yen-dollar rate. Interventions in this model work through providing information about the future course of monetary policy.

\section{The Model}

Consider a simple uncovered interest rate parity (UIP) equation for the exchange rate with no risk premium, where the expected change in the exchange rate over a $k$-period horizon is equal to the interest rate differential over the same horizon:

$$
E\left(e_{t+k\rfloor} \Omega_{t}\right)-e_{t}=i_{t}-i_{t}^{*}
$$

where $e_{t}$ is (the logarithm of) the price of the dollar in terms of yen, $k$ is the maturity of the interest rate, and $i_{t}$ and $i_{t}{ }^{*}$ are, respectively, interest rates in Japan and the U.S. Rewriting this condition as an equation for the current exchange rate without restricting the coefficients gives:

$e_{t}=\not E\left(e_{t+k} \Omega_{t}\right)+\beta\left(i_{t}-i^{*}\right)$

Under UIP, $\gamma$ would be equal to 1 and $\beta$ equal to -1 . Equation (2), generalized further to include a risk premium term, is the basis of most recent econometric models of the exchange rate. These models are usually estimated by replacing the expected value of the exchange rate by its actual value (see, for example, Wadhwani, 1999). In this paper we highlight the role of expectations by focusing on the rational expectations solution of (2). Under the assumption that $\gamma$ is less than one, which is required for stability, the solution of (2) is:

$$
e_{t}=\beta \sum_{j=0}^{\infty} \gamma^{j} E\left[\left(i_{t+j . k}-i_{t+j . k}^{*}\right) \mid \Omega_{t}\right]
$$

where expectations of the interest rate differential appear in $k$-period sequences because the order of the rational expectations equation is $k$. The implied long-run coefficient of the interest-rate differential in this equation is equal to $\beta(1-\gamma)$, which for $\gamma$ smaller than 1 , would be negative.

To compute future expectations of the interest rate differential, assume that this variable follows an auto-regressive process and, as argued above, is also influenced by announcements of interventions over a relevant horizon. Past exchange rates could also influence perceptions about the future course of monetary policy and are included in the equation. Representing interventions by $D_{t}$ we have:

$$
E\left[i_{t+j . k}-i_{t+j . k}^{*} \mid \Omega_{t}\right]=\sum_{i=0}^{h} \alpha_{i}\left(i_{t-i}-i_{t-i}^{*}\right)+\sum_{i=1}^{l} \psi_{i} e_{t-i}+\sum_{i=1}^{j} \lambda_{i} D_{t-i}
$$


This simple formulation abstracts from explicitly incorporating expectations of future interventions on current interest rates. ${ }^{8}$ Substituting (4) into (3) gives a dynamic equation relating the exchange rate to its past values, current and past values of interest rate differentials, and intervention dummies. This equation would have the following general representation:

$e_{t}=\sum_{i=1}^{n} \lambda_{t-i} e_{t-i}+\sum_{i=0}^{m} \delta_{i}\left(i_{t-i}-i_{t-i}^{*}\right)+\sum_{i=1}^{p} \eta_{i} D_{t-i}$

Although this relationship is loosely derived from a rational expectations model, it does not impose the restrictions implied by rational expectations on the coefficients. Note also that while interventions in this model are assumed to operate primarily through their signaling effect regarding future interest rates, empirical support for the model would clearly not exclude the possibility that interventions could operate through other channels as well-for example through the risk premium, as in Dominguez and Frankel (1993).

\section{Estimation of the long-run relationship}

The model leading to equation (5) can be estimated using the VAR methodology. Since both the yen-dollar rate and the interest rate differentials appear to contain unit roots ${ }^{9}$, it is necessary to test for a cointegrating VAR relationship. For simplicity, we do not include the intervention dummies in the long-run relationship, but only in the resulting short-run error correction model; including the dummies in the long-run relationship, however, makes little difference to the results. It is important to note in this context that since the yen-dollar rate is a non-stationary variable, any temporary shock to it will have an impact on its longrun path. Thus, a finding that interventions have an impact on the change in the yen-dollar rate during any particular period (see below) also implies that they have a long-run effect on the yen-dollar rate.

The tabulation below reports the results of the Johansen test for cointegration.

\section{Cointegration Likelihood Ratio for the Yen-Dollar Rate Equation ${ }^{1 /}$}

\begin{tabular}{ccccccc}
\hline & & \multicolumn{2}{c}{ Maximum Eigenvalue } & & \multicolumn{2}{c}{ Trace } \\
\cline { 3 - 6 } \cline { 5 - 7 } Null & Alternative & Statistic & $95 \% \mathrm{cv}$ & & Statistic & $95 \% \mathrm{cv}$ \\
$\mathrm{r}=0$ & $\mathbf{r}=1$ & 21.96 & 19.22 & & 30.74 & 25.77 \\
$\mathrm{r} \leq 1$ & $\mathrm{r}=2$ & 8.79 & 12.39 & & 8.78 & 12.39 \\
\hline
\end{tabular}

1/ Based on cointegrating VAR of order 4, with unrestricted intercepts, and restricted trend, which includes both the yen-dollar rate and the interest rate differential as endogenous I (1) variables.

${ }^{8}$ Given the discrete nature of the intervention variables and their dependence on past exchange rates (as modeled below), an explicit incorporation of their future expectations would make the model highly non-linear and intractable (see Pesaran and Samiei, 1995).

${ }^{9} \mathrm{ADF}$ tests of order 12 including an intercept and a linear trend gives a value of -1.67 for the logarithm of the exchange rate and -2.83 for the interest rate differential, against a critical value of -3.42 . ADF tests on first differences of the two variables gives -10.63 and -11.58 , respectively, against a 95 percent critical value of -3.42 . 
The estimations indicate that there is one cointegrating relationship between the exchange rate and the interest rate differential that includes a trend and an intercept term. Thus, the two variables move together in the long run according to the following relationship:

$e=0.165\left(i-i^{*}\right)+0.0003 t$. Note in this context that this result is not necessarily consistent with the strict UIP condition, which by requiring that $\gamma$ equals unity implies a long-run relationship between the interest rate differential and the change in the exchange rate. Moreover, if $\gamma<1$, as required by the stability condition for the rational expectations solution, then the relationship between the interest rate differential and the exchange rate should be negative. Although a positive coefficient for the interest rate differential is consistent with the findings of some other studies - which use lower-frequency data and/or have been estimated over different time periods ${ }^{10}$-restricting the coefficient to be small and negative is not rejected by the data, suggesting that a wide range of coefficients can give a cointegrating relationship. The multiplicity of potential cointegrating relationships, however, has little impact on the results on interventions in the next section.

\section{Error-correction and intervention dummies}

The data on daily intervention in the yen-dollar market obtained from news reports during 1995-99 are classified into 4 categories:

Type 1: BoJ intervenes to weaken the yen (incidence 32 times)

Type 2: BoJ and the Fed intervene to weaken the yen (incidence 6 times)

Type 3: BoJ intervenes to strengthen the yen (incidence 9 times)

Type 4: BoJ and the Fed strengthen the yen (incidence twice)

Representing each single intervention by a dummy variable should in principle allow us to test the effectiveness of every intervention made during this period. However, given the number of observations, adopting such a strategy would make the estimations unwieldy. On the other hand, the strategy of distinguishing the interventions only by the above four broad categories would fail to take into account the fact that not all interventions are equally effective. A close look at the data on interventions indicates that they tend to occur in clusters. Consequently, to distinguish better the effects of these clusters of interventions within each broad category, we subdivide them based on how they were bunched up during 1995-99. In the case of type 1 interventions, we identify 9 distinct intervention clusters, represented by 9 dummies, $D_{11}$ to $D_{l 9}$, each taking the value 1 in the event of an intervention of type 1 in that particular episode, and zero otherwise. In the case of type 2 intervention, 3 episodes are identified, $D_{21}$ to $D_{23}$; in the case of type 3 intervention, there are 4 episodes, $D_{3 /}$ to $D_{34}$; and finally in the case of type 4 intervention, only 1 episode, $D_{4}$, is identified. Thus, we define 17 intervention dummies altogether for the estimations. The expected signs of the coefficients on types 1 and 2 dummies are positive, and negative on types 3 and 4 . An examination of the exchange rate data suggests the presence of an important outlier-i.e., the substantial appreciation of the yen associated with the collapse of the carry-trades during August-October 1998. To isolate this effect, we include a carry-trade-dummy $-\mathrm{D}_{\mathrm{ct}}-$ in the

${ }^{10}$ See, for example, Wadhwani (1999). 
regressions to capture the largest exchange rate movements associated with this particular episode.

Table 1 presents the estimated short-run error-correction model of the yen-dollar rate, with the error-correction term calculated using the cointegrating relationship derived above, and including the intervention dummies and their one-period lagged values. In order to highlight the impact of interventions on the yen-dollar rate, a parsimonious version of the model that includes only the correctly signed significant dummies is presented in Table 2 . The results provide support for the hypothesis that interventions, on the whole, do make a difference to the yen-dollar rate, and that they have been successful on a number of occasions in changing the path of the exchange rate in the desired direction. Exclusion of the intervention dummies from the equation is strongly rejected by the data $[F(34,1549)=3.74(0.00)]$. Moreover, although as indicated by the R-squared, the estimated model explains only a small portion of the daily fluctuations in the yen-dollar rate, it clearly outperforms a simple random walk model, which would require that no variable has a significant influence on the change in the exchange rate. ${ }^{11}$

While the residuals in the above specification fail the normality test-as would be expected with high-frequency exchange rate data-alternative methods of estimating the model to deal with this problem suggest that the results are quite robust. Since an F-test does not reject the presence of Autoregressive Conditional Heteroscedasticity (ARCH) type effects in the residuals $(\mathrm{F}(6,1536)=26.01[0.00])$, the normality problem could be dealt with by estimating a Generalized ARCH (GARCH) model. We use the parsimonious specification of the model, as presented in Table 2 , to estimate a GARCH $(1,1)$ model. This model allows the conditional variance of the error term to depend on the absolute value of the residual in the previous period and its own lagged value, as well as the carry-trade-dummy. ${ }^{12}$ The results, reported in Table 3, indicate clearly that the significance of the interventions dummies is essentially unaffected by allowing for $\mathrm{ARCH}$ effects in the residuals.

The inference to be drawn from these estimation results is that interventions appear to have had a reasonable chance of success in the yen-dollar market, especially when they were coordinated. Out of the seventeen episodes of interventions identified in the analysis, eight appear to have led, within two days, to a significant movement of the exchange rate in the desired direction; and the remaining nine are mostly associated with no significant movements in either direction. This is a particularly noteworthy result given that interventions are, by design, likely to take place when the exchange rate is moving in an

${ }^{11}$ This result holds even when the carry-trade-dummy - which contributes significantly to the value of the R-squared-is excluded. While the inclusion of this dummy variable is justified on economic and statistical grounds, it cannot be treated as a genuine explanatory variable, given that it is defined ex post.

${ }^{12}$ The alternative of including the square of the residuals instead of their absolute value caused computational difficulties. 
Table 1. Estimated Error Correction Model of Interventions Based on Cointegrating VAR

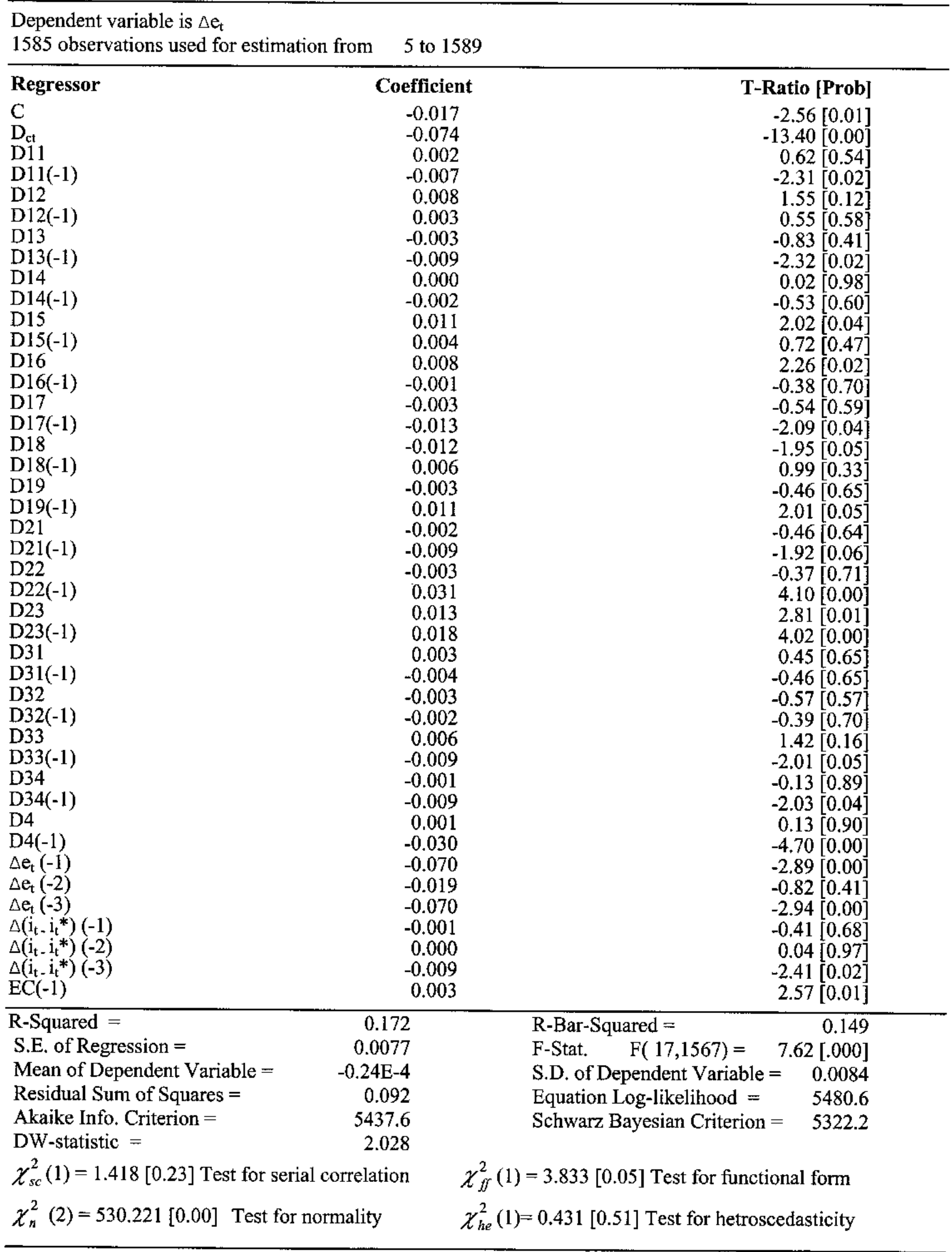

The dependent variable $\triangle \mathrm{e}$ is the change in the logarithm of the yen-dollar rate. $\mathrm{EC}$ is the error correction term from the cointegrating VAR reelationship. $C$ is the constant. The $D_{i}$ 's represent the dummies for different type of interventions as described in the text. 
Table 2. Parsimonious Estimated Error Correction Model of Interventions Based on Cointegrating VAR

Dependent variable is $\Delta \mathrm{e}_{\mathrm{t}}$

1585 observations used for estimation from 5 to 1589

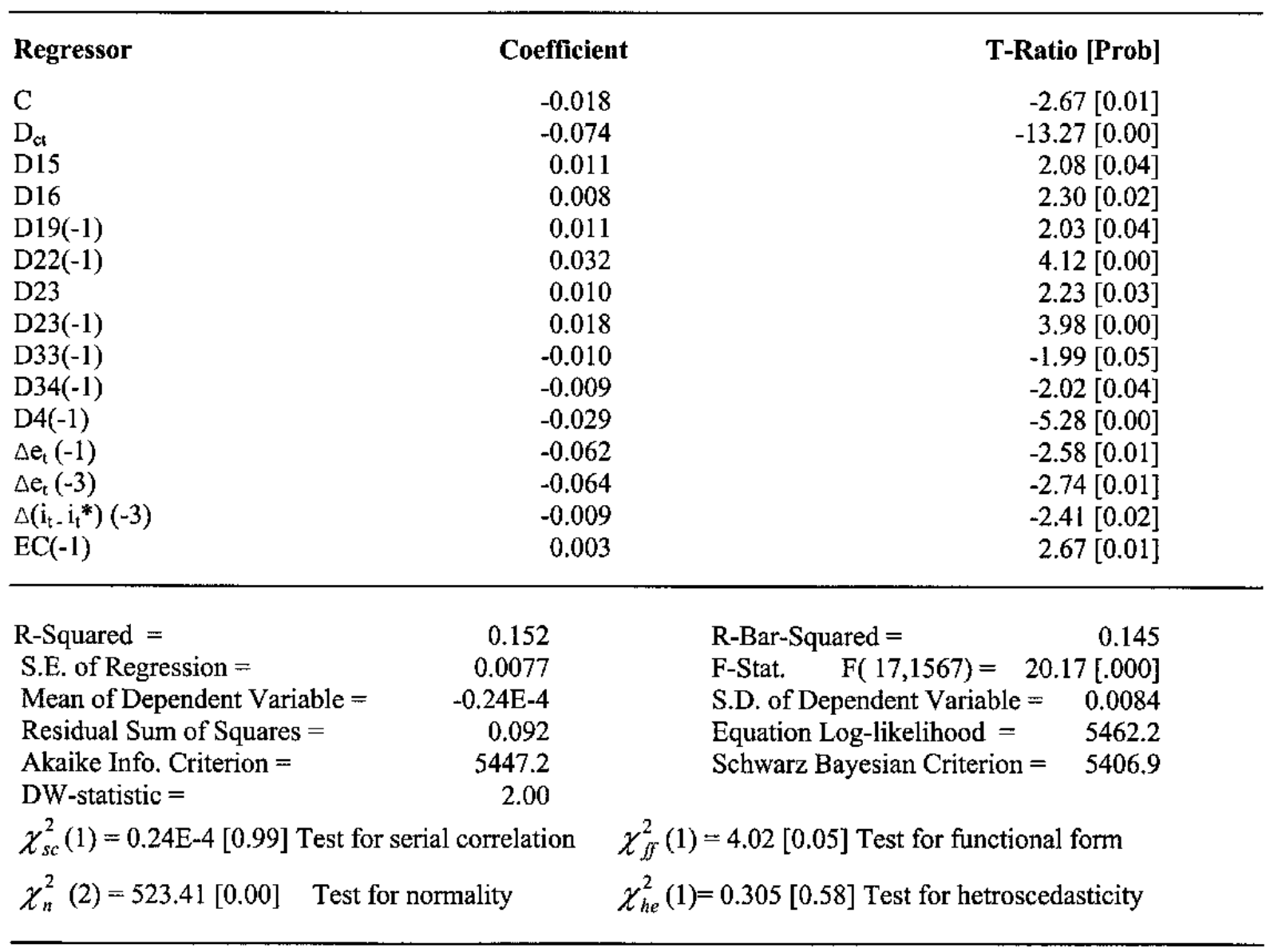

The dependent variable $\triangle \mathrm{e}$ is the change in the logarithm of the yen-dollar rate. $\mathrm{EC}$ is the error correction term from the cointegrating VAR reelationship. $C$ is the constant. The $D_{i}$ 's represent the dummies for different type of interventions as described in the text. 
Table 3. Estimated GARCH(1, 1) Model of Interventions

Dependent variable is $\Delta e_{1}$

1585 observations used for estimation from $\quad 5$ to 1589

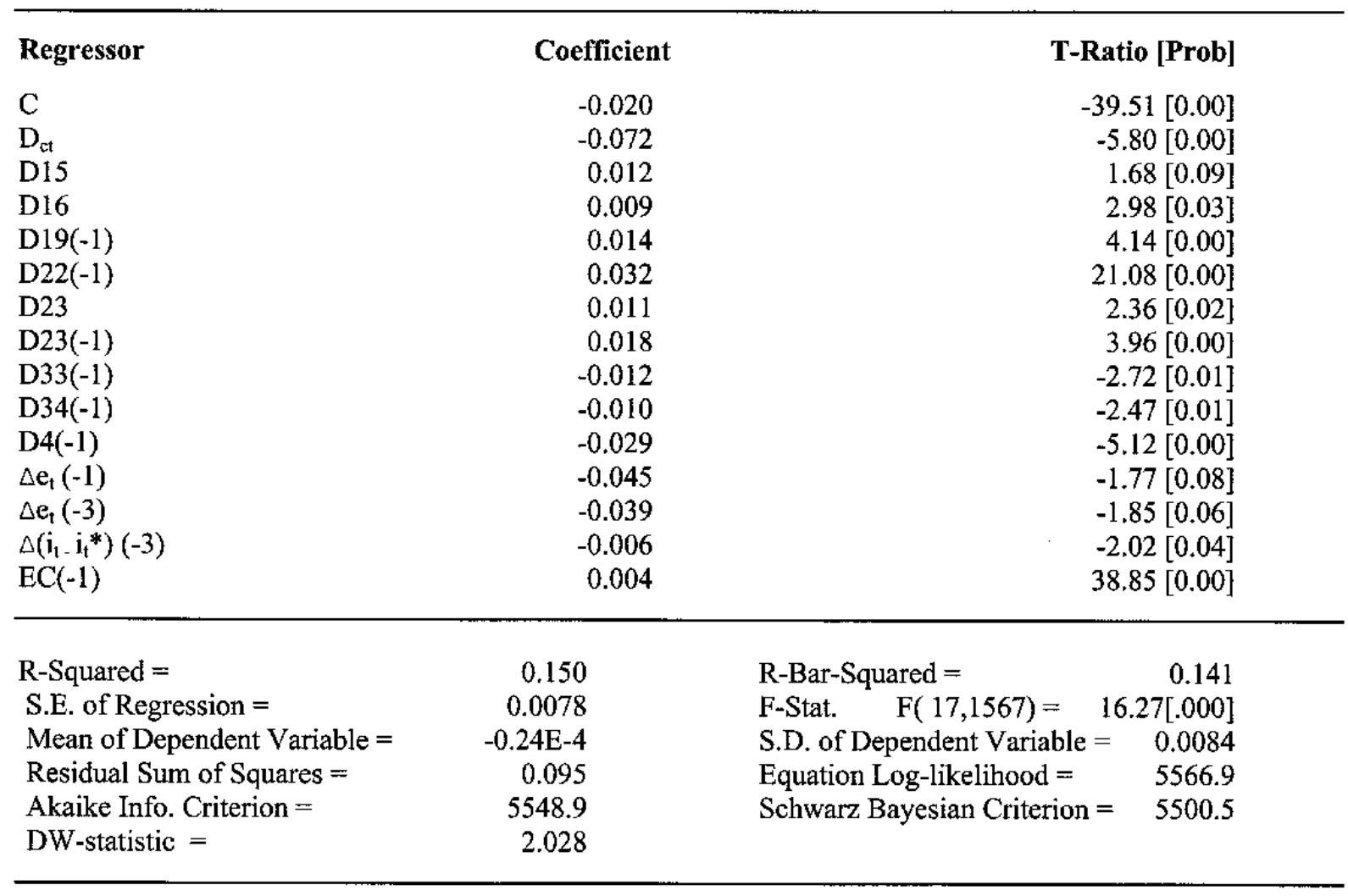

Parameters of the Conditional Heteroscedastic Model

Explaining H, the Conditional Standard Error of the Error Term

\begin{tabular}{lcc}
\hline & Coefficient & Asymptotic Standard Error \\
Constant & $0.260 \mathrm{E}-3$ & $0.326 \mathrm{E}-4$ \\
ABS $(\mathrm{E}(-1))$ & 0.106 & 0.015 \\
$\mathrm{H}(-1)$ & 0.886 & 0.011 \\
$\mathrm{D}_{\mathrm{ct}}$ & 0.004 & 0.003 \\
\hline
\end{tabular}

$\mathrm{H}$ stands for the conditional standard error of the error term.

E stands for the error term.

The dependent variable $\triangle \mathrm{e}$ is the change in the logarithm of the yen-dollar rate. $\mathrm{EC}$ is the error correction term from the cointegrating VAR reelationship. $\mathrm{C}$ is the constant. The $\mathrm{D}_{\mathrm{i}}$ 's represent the dummies for different type of interventions as described in the text. 
undesired direction, and hence, create a tendency for the estimated coefficients to be wrongly signed. That is, even when an intervention succeeds partially in precluding the exchange rate from moving further in the undesired direction, one would not necessarily observe a correctly signed estimated coefficient on the dummy variables. The fact that we observe the estimated coefficients on the dummy variables to be correctly signed and significant in about 50 percent of the episodes is a testament to the reasonable level of success achieved by interventions in the yen-dollar market.

The results also indicate that coordinated interventions tend to be clearly much more effective than unilateral interventions when it comes to both strengthening the yen as well as weakening it. The least effective have been type 1 interventions-attempts by the BoJ to weaken the yen - with only three successful episodes (the coefficient of either the dummy or its lagged value is significant with the right sign at 5 percent rejection probability) out of a total of nine. All other categories of interventions appear to have had a higher success rate than type 1 interventions. Two out of the three episodes of type 2 intervention have been successful, as have been two of the four episodes of type 3 interventions. The only episode of type 4 intervention also proved effective. In particular, the two successful cases of coordinated interventions to weaken the yen, lowered it by 2-3 percent against the dollar in each case $\left(D_{23}\right.$ and $\left.D_{33}\right)$. In the case of interventions to strengthen the yen, the only episode of coordinated action managed succeeded in pushing up its exchange value by 3 percent $\left(D_{4}\right)$. Unilateral interventions, in contrast, are associated with smaller changes in the exchange rate, generally by about 1 percent or less. The fact that unilateral interventions by the BoJ to strengthen the yen appear to have been somewhat more successful than interventions to weaken it poses interesting policy issues, given that interventions in the yen-dollar market have largely been unilateral actions by the BoJ to weaken the yen. It is necessary to emphasize again that, given the non-stationarity of the exchange rate variable, the short-run effects of the interventions captured in the regressions have persistent effects on the yendollar rate. Also, the significance of the intervention dummies is quite independent of the nature of the long-run relationship discussed in the previous section. ${ }^{13}$

The finding that coordinated interventions are probably more effective than unilateral ones can be related to the fact that the former provides signals about the future course of monetary policy in both countries, which is obviously of greater relevance to exchange rate determination. Moreover, coordinated interventions also provide implicit external sources of validation for the decision taken by each central bank to intervene, and motivate market participants to assign a higher probability to the expectation that the signals will portend changes in the future course of monetary policy.

Finally, an issue that is of interest to central bankers in this context is the so-called momentum factor. While interventions normally occur in response to unfavorable

\footnotetext{
${ }^{13}$ In particular, the absence of clear support for the interest rate parity hypothesis has no bearings for the short-run model, and removing the error-correction term from the equation makes little difference to the estimation results.
} 
movements in the exchange rate, central banks, in making choices about the appropriate time to intervene, may prefer to wait for a misaligned currency to move spontaneously for a few days in the desired direction, so that intervention can make use of the momentum in the exchange rate to push it further in the desired direction. It could be argued that interventions are likely to have a higher chance of success when momentum is present than when the central bank tries to lean against the wind. Testing this hypothesis formally in the dummy variable setting is not straightforward. Including interaction terms involving the cumulative change in the yen-dollar rate over a period prior to intervention and the intervention dummies can produce correctly signed coefficients which can, however, be the result of an ineffective intervention combined with prior movements of the exchange rate in the undesired direction (results not reported here). Given the ambiguities involved in using this methodology, an alternative approach is simply to check the data visually for the momentum factor. That, however, does not provide much support one way or the other about the importance of momentum. In particular, of the eight intervention episodes that appear to have been successful, only two or three could be considered to have taken place in an environment where the exchange rate was already moving in the desired direction for a reasonable period of time prior to intervention (see Figure 2).

\section{TRIGgERS FOR INTERVENTIONS}

There are two distinct sets of issues relating to the triggers for intervention in the yendollar market. The first is the question of why the BoJ intervenes so much more frequently than the Fed in the yen-dollar market, particularly when it comes to stemming yen appreciation. The second revolves around the search for patterns in past exchange rate movements that can offer clues about when the probability of interventions is high.

An intuitive answer to the question of why the BoJ intervenes much more frequently than the Fed would be that the exchange rate matters more to the Japanese economy than it does to the U.S. economy. This would indeed be the case if foreign trade played a more important role in Japan than it did in the United States. However, the exposure of the Japanese economy to foreign trade is broadly similar to that of the United States. The average value of exports and imports expressed as a percentage of GDP, a standard measure of the degree of "openness", was about 12 percent in Japan in the latter half of the 1990s, compared to about 14 percent in the United States.

Even though the exposure of the Japanese economy to foreign trade is marginally lower than in the United States, it still happens to be the case that fluctuations in the yendollar rate have stronger effects on the former than they do on the latter. Figure 3 offers clues to the source of this puzzle. Japan's nominal effective exchange rate (the exchange value of the yen against a weighted average of the exchange rates of trading partners) has tended to move closely in tandem with the yen-dollar rate. The dollar's nominal effective exchange rate, in contrast, has moved quite independently of the yen-dollar rate. The reason for this dichotomy lies in the fact that Japan trades with a number of countries that have linked their currencies to the dollar. Consequently, every time that the yen strengthens against the dollar, it also strengthens against the other currencies that are fixed to the dollar, which has the effect of dampening the external sector's support for the economy. Fluctuations in the yendollar rate, however, impact on the U.S. economy only in as far as they affect trade with 
Figure 2. Japan: Exchange Rate Interventions
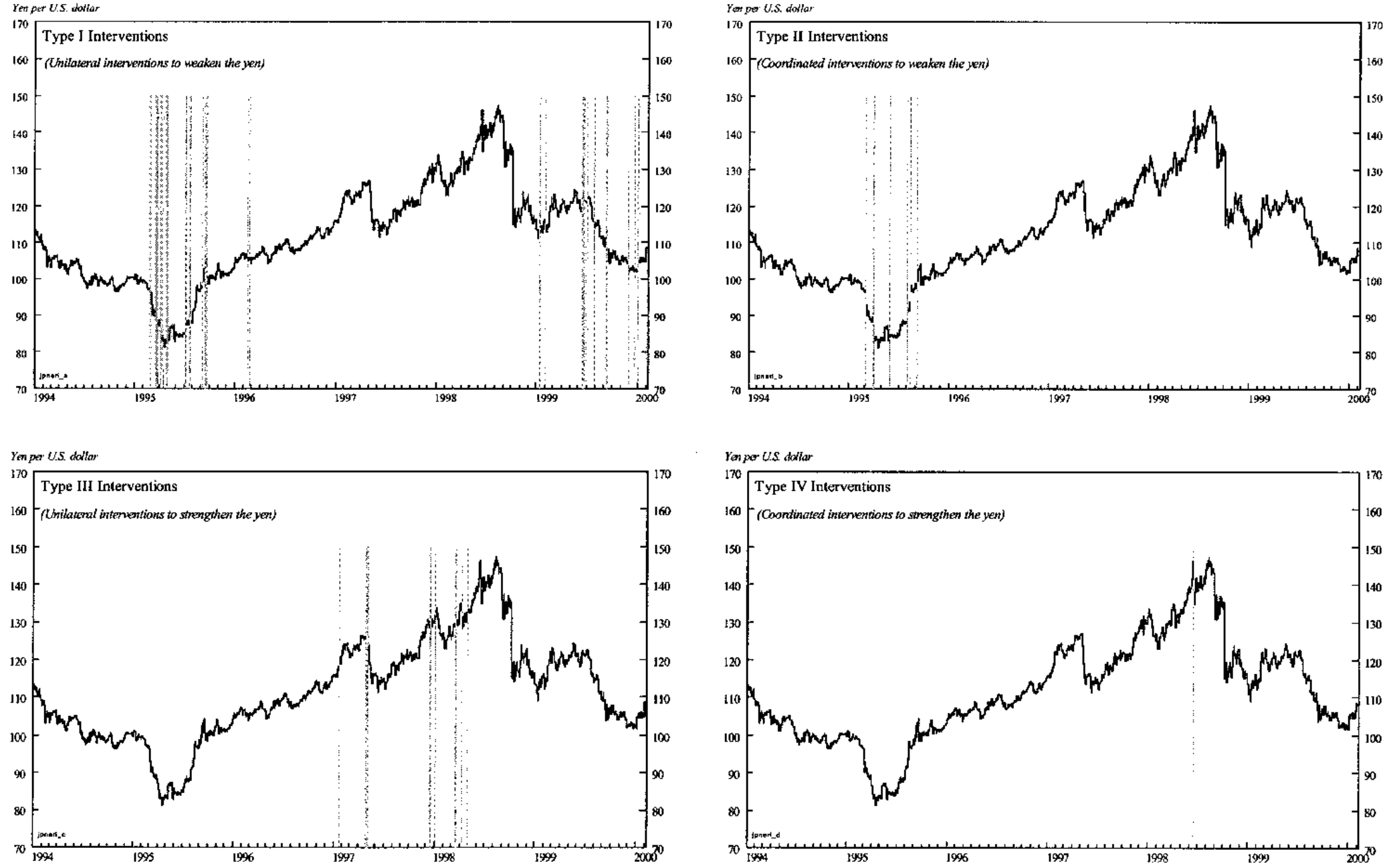

Sounces: Bloomberg, LP: and staff calculations. 
Figure 3. Japan: Exchange Rate Comparisons, 1985-1999
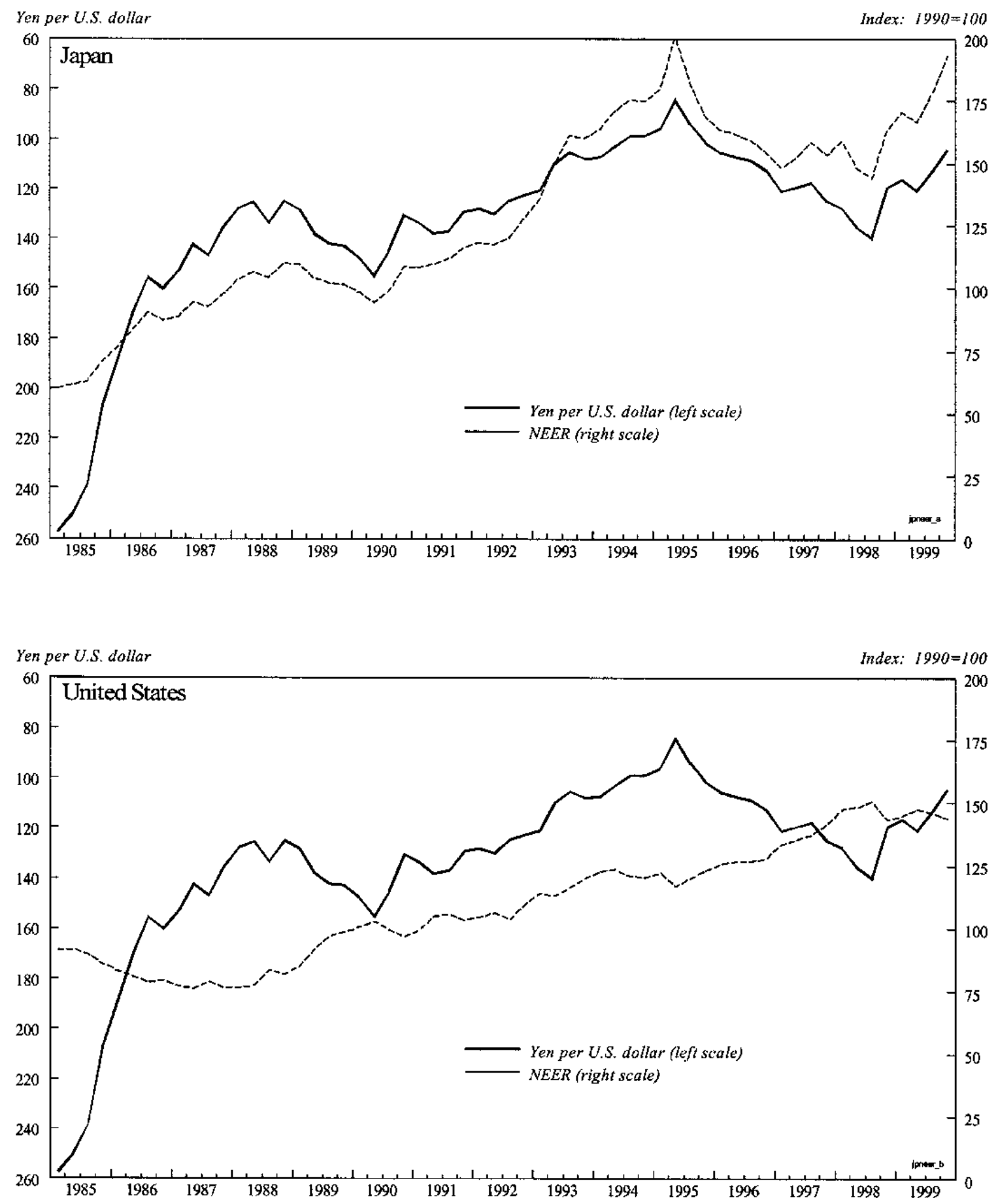

Source: IMF, Information Notice System. 
Japan. The relatively stronger impact of changes in the yen-dollar rate on the Japanese economy provides a plausible explanation for why the BoJ intervenes much more frequently than does the Fed.

What precisely sets off interventions in the yen-dollar market? Neither the BoJ nor the Fed are in the practice of providing detailed explanations for why they intervened in particular instances. The Japanese authorities, however, emphasize in their public statements that they do not target any particular value of the exchange rate; they claim, instead, to intervene primarily for resisting both an "excessive appreciation" and an "excessive depreciation" of the yen. An interesting issue to examine, therefore, is whether episodes of rapid changes in the yen-dollar rate have in practice triggered interventions.

Probit models provide a useful econometric technique for identifying the triggers for intervention. In this setting, the intervention event, $D_{t}$, defined as a dummy that takes the value 1 in the event of intervention (of any type) and zero otherwise, could be considered as the observed counterpart of the underlying smooth response variable, $D^{*}$, which responds linearly to variables such as the extent of the absolute change in the exchange rate during a specified period. Thus:

$$
D_{t}^{*}=\theta^{\prime} x_{t}+u_{t}
$$

where $x_{t}$ is the set of exogenous variables that influence the response variable, and $u_{t}$ is an error term. Then:

$$
\begin{aligned}
& D_{t} \quad=1 \quad \text { if } D_{t}^{*} \geq 0 \\
& =0 \text { otherwise }
\end{aligned}
$$

The system of equations $7-8$ can be estimated by the maximum-likelihood method. The absolute value of the cumulative change in the yen-dollar rate over the previous 5 days is included as an explanatory variable. The change in the exchange rate on the same day of the intervention is excluded to avoid simultaneity problems. The estimations also include the lagged value of $D_{t}$, and the results are reported in Table 4.

The estimated results of the probit model indicate that the Japanese authorities have in practice intervened to stem both an "excessive" appreciation and an "excessive' depreciation of the yen-dollar rate, consistent with their official pronouncements about exchange rate policy. It needs to be emphasized, however, that the probit model does not provide a complete explanation of the triggers for interventions. This is not surprising, given that the Japanese authorities are likely to be more comfortable with exchange rate fluctuations around certain levels of the yen-dollar rate than over others, even though there are no official pronouncements about what these zones of comfort are. Consequently, movements in the yen-dollar rate over some ranges are unlikely to provoke interventions in practice.

As discussed earlier, there could also be an asymmetry between how the Japanese authorities respond to yen appreciation and yen depreciation-being somewhat quicker to move when the yen appreciates rather than when it depreciates. Another factor that might 
Table 4. Probit Model of Triggers for Interventions

Dependent variable is the intervention dummy, $\mathrm{D}$

1583 observations used for estimation from 8 to 1590

\begin{tabular}{lcc}
\hline Regressor & Coefficient & T-Ratio [Prob] \\
C & -2.0646 & $-22.4899[.000]$ \\
D (-1) & 1.2102 & $5.8929[.000]$ \\
AE & 7.1924 & $1.9543[.051]$ \\
\hline
\end{tabular}

Factor for the calculation of marginal effects $=.062756$

Maximized value of the log-likelihood function $=-207.9102$

Mean of $\mathrm{D}=.032217$

Pseudo-R-Squared $=.077461$

The dependent variable $\mathrm{D}$ denotes intervention of all types. $\mathrm{C}$ is a constant, and AE denotes the absolute change in the yen-dollar rate over a five-day period. 
explain the relatively low explanatory power of the probit model is related to the fact that the exchange rate can, at times, move autonomously in the direction desired by the BoJ. For instance, the sharp appreciation of the yen following the collapse of the yen-carry-trades during the global financial crisis in August 1998, is an example of a rapid and sustained change in the yen-dollar rate that did not initially warrant any interventions.

The probit model indicates that interventions in the yen-dollar market tend to occur in clusters. Lagged intervention has a statistically significant coefficient, implying that if there has been an intervention today, then there is a good chance that there will be another one tomorrow.

\section{Concluding Observations}

As the Japanese economy attempts, haltingly, to pull out from a decade long stagnation, with short-term interest rates close to zero and fiscal stimulus having approached its practical limits, the role that foreign exchange interventions can play in providing support to the economy has gained attention. The findings of this paper indicate that there may indeed be a role for foreign exchange interventions in providing stimulus at the current conjuncture, given that interventions have succeeded on a number of occasions during 199599 in changing the path of the yen-dollar rate in the desired direction. Nevertheless, the impact that interventions can have on the economy needs to be put into the proper perspective, as the typical intervention when successful has a relatively small, though persistent, impact on the yen-dollar rate.

Both the BoJ and the Fed, like central banks in other industrial countries, routinely sterilize interventions. The fact that interventions in the yen-dollar market have made a difference implies that sterilized interventions, contrary to conventional wisdom, have mattered. The paper has argued that sterilized interventions work by altering market participants' expectations of the future course of monetary policy and economic fundamentals, and also by overcoming bandwagon effects. As the signaling effects of sterilized interventions are far more powerful than the portfolio effects, market perceptions of disagreements between central banks and the authorities in charge of intervention decisions have the potential to mute the effectiveness of interventions. The paper also finds that coordinated interventions are more effective than unilateral interventions - - they have a higher probability of success, and when successful move the yen-dollar rate by a larger margin (on average by about three times) than unilateral interventions do.

The BoJ intervenes more frequently in the yen-dollar market than the Fed does. This paper has argued that the higher frequency of interventions by the Japanese authorities is in part related to the fact, that unlike in the United States, Japan's nominal effective exchange rate moves in close synchronization with the yen-dollar rate. Consequently, when the yen strengthens against the dollar, it implies a stronger negative shock for the Japanese economy than an appreciation of the dollar against the yen does for the U.S. economy. However, the disconcerting finding in this context is that unilateral interventions by the BoJ to weaken the yen have had somewhat less success in practice than its actions to strengthen the yen. 
Official statements by the Japanese authorities often emphasize that they do not target any particular value of the exchange rate; instead, they claim to intervene primarily for resisting both an "excessive appreciation" and an "excessive depreciation" of the yen. The estimated probit model indicates that relatively large and sustained changes in the exchange value of the yen in either direction during 1995-99 did have a high probability of triggering interventions. And these interventions occurred in clusters-if there is an intervention today, there is a strong likelihood that there will be another one tomorrow. 


\section{REFERENCES}

Chang, Yuanchen and Stephen Taylor, 1998, "Intraday Effects of Foreign Exchange Intervention by the Bank of Japan," Journal of International Money and Finance, No. 17.

Corker, Robert, 1989, "External Adjustment and the Strong Yen: Recent Japanese Experience," Staff Papers, International Monetary Fund, Vol. 36 (June).

Cross, Sam, 1998, "All About the Foreign Exchange Markets in the United States," Federal Reserve Bank of New York.

Dominguez, Kathryn, 1998, "Central Bank Intervention and Exchange Rate Volatility," Journal of International Money and Finance, No. 17.

Dominguez, Kathryn, 1999, "The Market Microstructure of Central Bank Intervention," NBER Working Paper No. 7337, September.

Dominguez, Kathryn and Jeffery Frankel, 1993, "Does Foreign-Exchange Intervention Matter? The Portfolio Effect," American Economic Review, Vol. 38, No. 5 (December).

Humpage, Owen, 1999, "U.S. Intervention: Assessing the Probability of Success" Journal of Money, Credit, and Banking, Vol.31, No. 4 (November).

Krugman, Paul, 1991, "Has the Adjustment Process Worked?," Institute for International Economics, Washington, D.C., September.

Meredith, Guy, 1993, "Revisiting Japan: External Adjustment since 1985," IMF Working Paper 93/52 (Washington: International Monetary Fund).

Mussa, Michael, 1981, "The Role of Official Intervention," Group of Thirty Occasional Papers, New York.

Pesaran, M. Hashem and Hossein Samiei, 1995: "Limited-dependent rational expectations models with future expectations", Journal of Economic Dynamics and Control, December.

Wadhwani, Sushil, 1999, "Currency Puzzles," Bank of England, September.

Watanabe, Tsutomu, 1994, "The Signaling Effect of Foreign Exchange Intervention: The Case of Japan," in Exchange Rate Policy and Interdependence, ed. by Reuven Glick and Michael Hutchinson (Cambridge: University Press). 